\title{
"It's All about Confidence and How You Perceive Yourself": Musical Perceptions of Older Adults Involved in an Intergenerational Singing Program
}

\author{
Jennifer Hutchison, Carol Beynon \\ The University of Western Ontario, Canada
}

\begin{abstract}
This study explores and identifies the perceptions of older adults involved in an intergenerational singing curriculum that brought a group of 20 seniors together with a Grade 2 class of children in one small Ontario community. During six, one-hour sessions, the seniors and children experienced a carefully-designed curriculum that explored songs across various themes that served as a vehicle in fostering dialogue, musical discourse and shared learning among the participants. At the conclusion of the program, interviews were conducted, and seniors, children, and administrators were encouraged to share their personal musical narratives and background, in addition to their experiences from and about this program. There is little research that details the benefits of intergenerational singing, however observational and narrative data from this study, revealed a prevalent theme pertaining to the seniors' perception of lack of confidence, concerns about perceptions of themselves by the children, and musical inadequacy. In an effort to enhance singing education programs for every generation, these findings may provide the groundwork for social and musical considerations as program designers and leaders establish intergenerational music programs that facilitate optimal music engagement across the generations.
\end{abstract}

\section{Introduction}

As the current populace witnesses its largest percentage of growth within the seniors' cohort, it is imperative that the physical, emotional, spiritual, and mental well-being of the elderly are addressed. There is no doubt that a positive state amongst the elderly can enhance the holistic perspective and outlook of the individual, and by extension, the community at large; thus, the purpose of this paper is to address how a shared music curriculum in an intergenerational singing program, involving elderly residents and Grade 2 students, can describe the perceptions of seniors' attitudes and aptitudes toward singing and toward themselves ${ }^{1}$. Observations and

\footnotetext{
1 The study is part of the Advanced Interdisciplinary Research in Singing project (AIRS), funded by the Social Sciences and Humanities Research Council of Canada. Principal Investigator: Dr. Annabel Cohen, UPEI.
}

interviews with participants provided perspectives from seniors regarding the physical properties of their vocal tone, quality, agility and ability which revealed a lack of confidence leading to apprehension and disengagement in the singing program. Clearly, this reaction is the antithetic response to those seeking to enhance the quality of life and musical opportunities for participants. Therefore, in order to address the issues that arise from seniors' participation in intergenerational programming, a thorough examination of the factors of age-related physical changes and psychological factors surrounding the nature of confidence and engagement was a prerequisite to identifying and explaining behavioural tendencies and outcomes. The research study was guided by questions pertaining to the perceived benefits of intergenerational music engagement; the potential concerns experienced by seniors during an intergenerational music program; describing musical engagement for seniors; and, examining the relationship of confidence to vocal ability and how this may potentially affect interaction and engagement in musically social activities.

\subsection{Intergenerational Learning}

Beynon, Heydon, O'Neill, Zhang and Crocker [1] note that while extensive research details the mental and physical health benefits of intergenerational activities and programs, there is substantially less information with respect to intergenerational music. Of this data, the prevalent model is one in which children perform for seniors, rather than mutual participation in the music-making process. Although formal intergenerational programming in music has been in existence in North America since the late 1970s, many models that do combine children with seniors tend to do so with a focus on a culminating public performance. In existence are even fewer studies related to intergenerational musicking combined with curricular connections.

As a result of Small's [2] quest to examine the nature and function of music in life, he suggested that the essence of musical meaning may not necessarily be found in the score, but "in the real world where people actually make and listen to music" (p. 11). His supposition that musical meaning is not necessarily tied to musical objects, but that a musical work exists for it to be performed in a social context 
altered the way in which he conceived of the word "music" itself. For Small, if music is not a thing, but an action, then the word music should not be a noun, but a verb, in order to express the broader idea of taking part in a musical performance. Therefore, "to music is to take part, in any capacity, in a musical performance" (p. 12). In accordance with Small's encompassing model that includes participating in any musical experience, it is assumed that this study's attempt to unite two generations in an environment of shared singing would qualify as "musicking". Small outlines the various forms that constitute participating in the music process - from immersion to peripheral participation that encompasses all facets associated with listening, performing, composing, conducting, managing, organizing, advocating and administrating. His approach does not afford preference to certain forms of participation, thereby attempting to abolish the hierarchical notion that can be attributed to one's involvement in music. It is this recognition of equating all forms of music involvement that shows that engagement in music may also manifest itself in various forms.

In its most basic form, engagement is described as the connection between an individual and an activity of interest [3] and reflects the individual's active involvement or participation in the activity [4]. As Small would likely credit all forms of musicking equally valuable, one must recognize that engagement in singing may likely assume various forms and is experienced on an individual basis; one cannot assume a participant is engaged or not engaged based on the degree of involvement or the outward expression of this engagement. The outcomes of participation, be they of an educative or personal fulfillment nature, present themselves in varying degrees and present difficulty in assessing the correlation between one's role in music, one's degree of involvement, and ultimately, one's overall engagement in the process.

The benefits of intergenerational programming, as distinct from intergenerational activities, is crucial to providing a means by which experiences and interactions become significant to one's life [1], [5]. Further essential criteria for successful intergenerational programming describes it to "be beneficial to all [participants]", "be on-going, lasting for a significant length of time to establish relations", "serve the community", and include a curricular...component" [1] (p. 105). Of additional note, is that Harste, Woodword and Burke [6] described learners as "curricular informants" within the educational milieu, where learners are valued for the contributions they bring to the educative process. When subject matter is situated within the context of the learners' previously acquired knowledge and experiences then the learners become the vehicle for their own learning. As such, it is a priority for the intergenerational singing program to establish an environment in which the learners themselves "can experience and come to value" [6] (p. xii) the music that is significant for them. In this study, collaborative learning sessions were arranged whereby participant input influenced the shared textual, verbal and musical dialogue, and in this respect, we found children and seniors did function as "curricular informants".

\subsection{Seniors' physiology and aging}

Aging is defined in scientific terms as the "complex conglomeration of biological events that change the structure and function of various parts of the body" [7] (p. 157). Thus the organization of an intergenerational singing program must factor in the physiological considerations of combining the elderly with children, not only concerning singing and musicking, but also with regard to physical abilities. The issue of aging presents physiological challenges to the older adult, which impacts the curriculum in terms of planning as well as vocal and repertoire accommodations. Numerous studies report the inevitable physiological changes that accompany the aging process and often suggest that biological age based on the physical condition of the body, is more useful in measuring the deterioration of the voice than chronological aging due to the variance in the symptoms and effects of presbyphonia or agerelated voice changes [8], [9]. While many researchers have examined the noticeable changes in the speaking voice that accompany the aging senior, one can extrapolate that all of the issues noted, will manifest themselves in the singing voice as well.

The general characteristics of the aging voice include breathiness [10], [7], range loss [7], change in vibrato characteristics [7], development of tremolo [10], [7], loss of breath control [7], vocal fatigue [7], pitch inaccuracies [7], hoarseness [10], and "other 'undesirable' features" [7] (p. 156). With specific relation to singing, Meredith [11] described the agerelated functional changes that occur: inhalation becomes more shallow, exhalation and support can become weaker, phonation can become more airy, and resonance and text projection changes as the resonators and articulators are altered. While these characteristics have been documented by others as common audible changes in the voice, it is important to recognize that these changes do not go unnoticed by the aging singer. Frequent complaints made by seniors relate to the lowering and reduced range in females and the opposite in males, as well as vocal fatigue and voice tremulousness [8].

While physiological factors play a significant role in affecting vocal output, it is important to note that other contributing forces are in motion. Sataloff [9] reports that personality changes, mental disorders, mood disorders, sexual dysfunction, and malnutrition 
can potentially have adverse effects on the voice. While these disorders impact the larynx and brain directly, one must also consider that the medications used to treat various medical conditions play an indirect role on the vocal mechanism or on another anatomical site [9]. The drying effects of these medications [8], [12] can impose an additional burden to the challenges that already face the aging singer.

Although there has been much research regarding how professional singers age and what the necessary implications and remedies are to achieve maximum vocal potential [7], information that pertains to the untrained voice in an informal intergenerational singing environment is limited. However, the vocal needs and considerations of seniors who are involved in a weekly intergenerational singing program present different challenges than the predominant research being conducted on the aging professional singer. Even though the timing, degree and intensity of physiological changes vary from person to person, ultimately they are usually inevitable [11] and therefore must be addressed when engaging seniors in any singing endeavour. The phenomenon of increased life expectancy calls for more investigation and "those who research the voice admit there is still much to learn about changes in the singing voices of geriatrics" [13] (p. 51).

During the course of this IG singing curriculum, while the researchers observed and the senior respondents reported numerous benefits, one of the major concerns noted was a lack of confidence and sense of self-doubt in their personal abilities to be successful.

\subsection{It's all about confidence}

The implementation of an intergenerational singing program combined with physiological considerations raises questions about how confidence is perceived and portrayed in the sessions by participants and observers (i.e., children, researchers, staff). Studies about the aging voice suggest that even though changes in the voice are considered to be an inevitable component of aging, this process "appears to be a significant disability to many older people" [8] (p. 70). An examination of the literature reveals extensive work in the physiological functions of the aging voice and how this may carry psychological implications. The relationship of physiological and psychological health becomes apparent with the identification that loneliness and separation from family during the elderly stage are factors that "tend to exacerbate voice symptoms" [14] (p.288). Furthermore, tension, anxiety and depression are potential contributors to voice problems within this aging cohort [14]. It is reported that aging singers can become frustrated with their loss of vocal ability and begin to overcompensate for their vocal deterioration [15]. There are a number of clinical investigations that identified a large number of elderly persons who complained of vocal difficulty, centred around pitch, loudness and quality [8]. For these reasons, "many elderly individuals seem to be troubled by voice changes associated with senescence" [8] (p. 72), which can be described as the normal functional decline that takes place in the human body over time [16].

Although it may be apparent that the role of the voice in communication is essential, one cannot underestimate the importance of communication skills in the elderly as it may be "one of their most important avenues of socialization" [8] (p. 75). The fact that the voice is central to communication and that people are "empathetically engaged by the sound of the human voice at every stage in its development," [13] (p. 51) suggests that individuals would desire a positive portrayal of their personality reflected in their projected voice. If listeners report that the characteristics of the elderly voice are: lower vocal pitch, increased hoarseness or harshness, increased strain, vocal tremor, increased breathiness, reduced loudness, slower speech rate, greater hesitance, less precise articulation and longer duration of pauses [13] then the voice clearly becomes an identifier of age. According to Breytspraak (1995, as cited in [16]) the motivating factors that shape behaviour as people age are the desire to view themselves positively and to present a good image of themselves to others while also maintaining their sense of self in the face of a changing social environment. The connection between voice and personality is one not to be ignored. Caruso et al. [8] advocate that "the voice is a mirror of personality and senescence may cloud the image" (p. 75).

Identified physiological changes can extend beyond immediate effect of confidence into concerns about overall enjoyment in life. Investigations into seniors' increased level of lifetime satisfaction after engaging in singing classes [9] may suggest that an improvement in the perception of our ability to sing can indirectly or directly affect our perception of overall life satisfaction. It is reported that these classes produce a positive learning experience whereby the outcomes include increased selfconfidence and self-actualization [9]. Rayapati's study of seniors aged 63-79 revealed that one participant joined a group singing class in order to increase his confidence while singing in the church choir [17]. Clearly the value of joining group singing classes has the potential to increase confidence with respect to the singing voice and life enjoyment. This increased confidence can manifest itself in the form of courage to sing solos [17], [9] seeking challenging repertoire in various languages and participating in new musical experiences, including voice lessons and community ensembles [17]. There is however, a 
void in the research of confidence in relation to intergenerational singing programs, thus encouraging the need to examine the role of senior confidence in social singing situations with younger children.

What remains to be addressed is the outcomes of seniors' confidence related to singing when they are grouped alongside children in an extended program of musicking. Is there an impact on confidence as a result of IG singing? This particular setting may identify issues and concerns that do not necessarily surface in seniors when they are only involved in senior singing ensembles, or when children perform for them.

\section{Methodology and data collection}

This qualitative study examined interrelated topics of senior physiology, engagement and confidence that surfaced as a result of intergenerational music programming, and examined questions and issues surrounding the relationship between seniors' perception of vocal ability as it influences their levels of confidence, their degree of participation and engagement. The program involved 20 residents ranging in age from 67 to 101 from a retirement home and a Grade 2 class of 18 students from the local public school in a small Ontario city. Six weekly sessions, lasting about 50 minutes each, were planned (one of which had to be cancelled because of weather), in which songs were performed across various themes that acted as links in fostering dialogue, musical discourse and shared learning among the participants. After the program ended, interviews with children, residents, teachers, the school principal and retirement home staff were conducted through which participants were encouraged to share their experiences of the program as well as their personal musical experience and background. The aim was that in taking into account various perspectives, the researchers could extract significant data with respect to varying interpretations of the experience across a generational span. Consent was obtained from all members to be interviewed whereby the assurance of confidentiality was provided.

Structuring the program to include multiple sessions allowed for a collection of data, including video-recording of each session, ongoing observation by the senior researcher and two graduate students, field notes and in-depth individual interviews. The field notes included detailed depictions of the sessions, conversations, non-verbal reactions, musical events and atmospheric features of the physical environment. For this particular paper, the data from the interviews with the seniors was used; their interviews followed a flexible, semi-structured protocol and lasted approximately 45 minutes. During the interviews, the participants were prompted with questions pertaining to their musical backgrounds, their previous engagement with music, and their experiences and feelings arising from the intergenerational music sessions.

\section{Findings}

The data revealed several overarching themes that fell into 1) the benefits of participating in the program and, 2) the challenges associated with intergenerational music making. Seniors expressed the benefit of having the opportunity to reminisce through songs, to revisit singing, to connect with children, to participate in social interactions, to teach the children and to reap physiological benefits by feeling energized during and after the sessions. Many seniors enjoyed reflecting on the memories associated with certain songs. For example, remembering family gatherings and the spiritual connection to sacred hymns were positive outcomes for them of the music sessions. In connecting to specific songs, they were able to revisit a time in their lives when singing and music seemed present and important. With regret, many residents admitted that they rarely have the opportunity to participate in musicking at this stage in their lives. Significantly, it is these musical opportunities that potentially lead them into engaging social situations, whereas often seniors can experience feelings of isolation resulting in withdrawal from others and their surroundings [16]. The prevalence of resident comments focusing on group singing and its reciprocal benefits suggest that the collaborative musical environment is rewarding on a social level. Specifically, the collaboration with the primary children encouraged seniors to reflect upon the importance of connecting to the younger generation, not only because they believed they had a lot to teach the children, but that there was the recognition of the physiological and spiritual benefits for themselves at the conclusion of each session.

Conversely, there were significant challenges identified that surfaced from these sessions that the seniors felt clouded their ultimate enjoyment in the singing. Such themes include: previous attitudes toward singing, difficulty learning new repertoire, changing vocal physiology, medical limitations, emotional discomfort with songs, fear of singing alone and the disappointment in the apparent lack of engagement of their fellow residents. The interviews allowed the residents to reflect upon their own singing ability throughout their lives, whereupon many expressions of doubt and inadequacy regarding their lack of talent revealed apologetic and compensatory attitudes. As many recalled anxieties of their inferior voice quality as children, these feelings were then exacerbated by the acknowledgement that their senescent voices presented greater challenges than ever before. The identification of sensory impairments, mobility 
issues, memory difficulties and respiratory problems presented barriers to singing with children who did not experience these obstacles. While physiological considerations presented challenges to the seniors, it was noted by several that the emotional connection to songs that stirred their souls and memories, and the fear of possibly having to sing alone for others, acted as impediments in active involvement and full engagement during the sessions.

The research indicates that personal perceptions of aging are formed from social attitudes toward seniors, physical decline and the perceived loss of one's social role [16]. These characteristics revealed themselves in this project particularly through researcher observation from the seniors' behaviours, interactions and comments. These concerns were translated into their desire to be liked and accepted by the children, their expressed concern of the impediments that their medical limitations caused to their vocal abilities and the assertion of redefining their roles through their need to teach and nurture the students.

\subsection{Social considerations}

These seniors emphasized the social benefits of the program. For example, Bill likes the social aspect of singing, while Betty loves singing because she loves music and loves hearing people sing together. She noted that "I think music warms you up and brings people closer together." Philosophically, Joan commented that "Singing is a wonderful thing that we have as human beings - to express ourselves in that way." She finds it a happy way to share happiness with others. The program brought some assurance to Joan who said, "I feel more confident now belting it out with friends having a sing song," but added that she does not want to sing alone. Lois, Joan and Jane concurred that singing was a way of bringing people together and having fun because there's a natural and spontaneous camaraderie that develops. Of course, the social aspect of the program creates potential vulnerability for judgment that is identified as one challenge to aging in regards to social attitudes directed toward seniors. Occasionally, participants articulated anxiety pertaining to perceived social disproval from the children based on the seniors' musical preferences or desires, although this was never obvious during observations. Social disapproval may have been a concern, but not a reality. An example of this reservation was seen in Jane's conscious decision to refrain from singing an ending to a song "Heart of My Heart" that was unfamiliar to the students. She remarked that "if I did that during the session the kids would run the other way." While verbal disapproval was a worry, physical rejection was also a concern. Essentially, the social aspect of the project exposed the seniors to that possibility as was experienced by Irene when her child partner of the first week did not sit with her the third week. However, Irene had to be away during the second session for a medical appointment and the child had to sit with someone else. Irene's disappointment was a clear indication of vulnerability and the fear of rejection.

Another behavioural tendency of vulnerability was noted by researchers, after one song brought one resident to tears; "Somewhere over the Rainbow" had elicited an emotional response that left her feeling embarrassed and homesick for her grandmother who used to sing that song to her. As such, some seniors will don a mask to avoid drawing attention to one's self. Inevitably there appears to be a desire to retain a sense of personal control they may have possessed at an earlier age. Furthermore, their apprehension in appearing outdated to the younger students was made clear in their hesitancy in expressing that they did not know the songs that the children chose. As such, they would often join in an attempt to sing the song even if they did not know the words or tune. It was observed that the seniors were hesitant in volunteering answers and suggesting songs for fear that their choices might not be known or respected. On the other hand, they could be seen frequently leaning over to a child partner and whispering the answer in his/her ear so the child could answer. As a result, the need for positive reinforcement from peers, children and program leaders suggests there is a need to feel validated and respected for any contribution offered. Finally, demonstrated apprehension for making musical errors manifested itself in the cautious approach many seniors displayed when learning new songs. While the children eagerly joined in when faced with new songs or lyrics, the seniors expressed considerable hesitancy in participating under these circumstances. Furthermore, hesitation was observed with respect to senior initiation of musical discourse and in some instances, prevented residents from participating at all. Several residents elected to sit on the sidelines and if they were "caught" joining in the singing they immediately sought approval from the researchers that they were singing alright. In spite of the fact that our response was an enthusiastic "yes", this behaviour continued each week, and revealed a sense of vulnerability in the seniors as they seemed to fear potential exclusion on the basis that their skills and knowledge would be seen as outdated and unpopular to the younger generation. Along the same lines, researchers noted an emotional fragility when the senior residents were presented with songs that conjured up memories. In some instances, participants revealed that when they are affected by a song, they are unable to sing. The emotional connection to songs for seniors created a physical barrier to musical and emotional release. In 
a social context, this seemed to threaten the seniors' desire to retain a sense of authority and self-control.

\subsection{Physical considerations}

Rowe and Kahn [18] describe successful aging as including the facets of maintaining active engagement with life, as well as high physical and mental functioning. A second challenge then in successful aging pertains to physical decline [16]. Several participants alluded to personal observations of vocal decline and medical conditions that impair their ability to sing as well as they would like. Bill said simply that his voice was not as good as before, while Betty and several others commented that it has become harder to sing as they get older since they experience hoarseness and weakness in speaking and singing. Julie said: "My voice cracks and I get croaky, even when I am speaking." Joan and Irene expressed frustration with their inability to sing high anymore and are resigned to becoming listeners rather than singers. Lois said that her voice quality has changed and sounds old. Hearing loss was another comment made by several. "I can hear what I'd like the sound to be in my head, but I know it's not going to sound the same when I sing it with my voice," recounted Betty. Loss of memory, confusion, breathing problems and asthma also presented issues for many of our older singers.

The majority of senior participants interviewed acknowledged the negative physical and audible changes in their vocal quality and production. Descriptions identifying "hoarseness" and difficulty singing in their higher registers were expressed. During the second session, Lee was asked by the researchers to sing a song that was special in his heart. He immediately asked for water and worried that he would start in the wrong key. It is evident that Lee was concerned with the tone quality of his voice and his ability to sing the notes in his comfortable register. However, when he did sing, he sang "Heart of My Heart" with confidence and energy. Other seniors joined in while the children listened in awe, then asked to learn the song too.

Several times in the sessions, the difference in range of the songs for children and seniors and their inability to sing in each other's range was evident. The children were unable to sing as low as required when some seniors began the songs, while often the seniors could not sing with the children because they sang too high, and the seniors would stop singing to listen. When the desired vocal range of the seniors is not compatible with that of the children's physical vocal abilities, then the issue of song selection that is comfortable for both generations is of prime concern. Furthermore, the ramifications of the seniors' changing vocal physiology are significant in consideration that social behaviour may be affected by these perceived difficulties while participating in a singing collaborative initiative. It was also observed in many sessions that seniors often seemed more engaged and confident participating in songs that required instruments or actions because they could be seen as participating in the music activities without necessarily having to use their voices

\subsection{Considerations of social role}

The final challenge with respect to successful aging relates to the perception of social roles and that was evident by the respondents' comments during the study. Many seniors felt that their role revolved around teaching the students. As Bill stated, "The main goal of joining together is to teach the children something." That "something" assumed different forms for each resident. For Bill it was to teach the children that people get older, but that they still want to listen and be with younger people; for Betty, the lesson was a moral one of helping "the kids know right from wrong." Similarly, Joan suggested that "the goal of the sessions was for the children to learn from the adults' comments and suggestions." Interestingly, while the seniors saw these classes as important learning opportunities for the children, they seemed not to acknowledge or recognize that learning was important for them too. In some instances the seniors felt that they needed to prove to the children that seniors are people too. Joan expressed the benefit for children to see that the seniors are "not old fogies, we like to sing as well... and we like to have fun too." Mirroring this sentiment is Jane's response that "I hope that they learned to be comfortable around older people." Finally it was Keith's and Lois' hope that the children would have a better appreciation for what seniors are like, become comfortable helping the aged as they grow older, and to get them interacting more with seniors who they might not know.

The seniors envisioned their role as nurturing and educational. Irene, Lois, Kevin and Keith discussed the importance of just being there with the children to offer support, help them, and be a friend to them. Kevin recognized the mutual benefits in this support: "I think that's important for me and it's important for the kids that they have this type of friendship support." In addition to supportive companionship, Keith felt that he "helped the children with their ideas and to come out of their shells and participate," Joan felt that the children were able to learn "a bit more self-esteem" as a result of senior interest in their lives and Lois believed that encouraging the kids to "lead the way and to go with them and to make them feel important" helps them develop confidence.

Keith was the only senior to comment on his role as it related to music: "The benefit of helping the children with singing is that it stimulates them for developing a love of music," although Irene did 
indicate that her role was to entertain the children and help them along. This entertainment took the form of dressing up in costume for the harvest celebration party, providing decorations and supplying candy. While there were some moral and educative lessons offered by some seniors, clearly the seniors viewed their roles as social educators, who supported, encouraged and nurtured their young partners, so that ultimately the children were the beneficiaries.

Throughout the sessions, the seniors prompted students with their answers, suggesting ideas for their tasks, assisting them in drawing, spelling or writing, and working collaboratively on projects, all while keeping the children engaged with questions. Additionally, the seniors would continually offer words of encouragement and applaud after a student sharing session. The seniors' recognition of their supportive and educative role was demonstrated numerous times as they would abstain from answering a question so that the children were provided the opportunity to respond. The seniors rarely volunteered which suggests their desire to allow the students to shine and would always allow the students to choose songs that represented the group around the table, regardless of whether they knew the songs or not. When the groups were assigned the task of coming up with song titles or new verses to add to existing songs, inevitably the song title of lyrics would be determined and shared by the students. Generally speaking, the only time the residents would raise their hands was to volunteer their child friend. There were several instances whereby if the students were unable to answer a question, their "Grandparent" friends would whisper the answer in their ears so that they could respond.

Many seniors embraced the surrogate "Grandparent" role as was demonstrated by bringing candy and sneaking it to the children at the Harvest Celebration party. In a similar fashion, the residents assisted the children with their coats, boots and shoes and even offered friendly advice for the children to wipe their hands on napkins, rather than their clothes. It was observed that the seniors felt especially useful when they were given the role of the caregiver, partly to establish a sense of purpose, but to also be relieved of the pressure of participating when the task is no longer focused on singing. Several comments from seniors throughout the project indicated that they feel they are not as much value to the students in this process as the students are to them. This tendency to downplay the importance of their role suggests that they may be hesitating in putting themselves out there to face rejection. Also, when asked about the purpose of the session, the seniors were quick to point out that the children were engaged in learning, but did not acknowledge that these sessions were also learning opportunities for them. While not surprising, these findings raise an important question as to whether these physiological observations relate to seniors' confidence levels, behaviour, social interaction and singing involvement when they are matched with a group of young singers who do not share the same concerns.

\section{Discussion}

Research about aging outlines the important role that the sense of self has to successful aging [16]. "The self's sensitivity to others' perceptions can make ageism a painful experience" [16] (p. 142) and lower a person's self-esteem. Therefore, senior involvement in a group singing program that involves peers, researchers and children can place them in a vulnerable situation that is potentially riddled with judgment. In several instances, comments were made by the seniors referencing the fact that these students seem really smart and that they (seniors) certainly didn't know as much as the kids did at their age. The awareness of the students' cognitive ability may also result in heightened fear of being judged as having little value to the children or to the outcomes of the IG singing program.

Secondly, Novak reports that physical decline is also a factor in challenging a person's sense of self [16]. The physiological observations made by the participants and observers are consistent to those discovered in previous investigations of the senescent voice. Abeles (1996, as cited in [16]) found that the elderly tend to define themselves in relation to their current concerns, especially if they are health related. If seniors are concerned of a physiological nature, then this concern and doubt will be transferred to how they perceive themselves. A lack of confidence in their vocal and physical health can therefore translate into social situations where this confidence or lack of confidence can be observed. As a result, it can be concluded that the seniors involved in this project are susceptible to feelings of self-doubt.

Finally, "role loss can rob a person of self-worth" [16] (p. 142) as social roles establish one's status and provide a purpose. If the loss of a role threatens a person's well- being [16], then the observations that the seniors assumed nurturing roles while affirming that they were able to teach the students lessons, demonstrates their desire to assert themselves in a social role.

An examination of the findings from an interpretive perspective allows researchers to understand how people interpret their social world, how they interact with one another and helps to explain why they do what they do [16]. As such, recognizing that in an environment of IG singing, seniors may feel vulnerable to judgment, both physiological and social in nature, can potentially 
explain behaviour and reflection that portrays a lowered level of confidence. Ultimately, these factors may affect one's overall level of engagement in intergenerational singing programs.

The consistent observations of researchers noting the tendency for many seniors to choose to observe from the sidelines, rather than immerse themselves with the children indicates a connection between a low level of confidence in musical and/or social skills and full musical engagement. Several residents needed to be encouraged, invited and recruited to attend the music sessions. Many were initially excited because they thought they would be passive spectators of a children's choir, but grew apprehensive and reluctant to participate when they recognized that there was an element of involvement required of them. It could be suggested that there is a level of comfort associated with being able to isolate one's self from the group and be an observer; having the opportunity to be involved in voluntary participation, rather than forced obligation. This desire to engage in peripheral musicking became evident as musicians invited and hired to perform for the residence drew a larger crowd than the intergenerational singing program. However, these observed performances resulted in a silent, listening audience with no interaction. The pressure to participate and contribute in a meaningful way was reduced by the changed role of an audience member rather than that of learner, contributor, and "curricular informant".

Even though there were several impediments to their confidence, the seniors reported significant musical engagement and enjoyment in the project. They demonstrated behavioural tendencies that indicate an ability to cope with less than desirable circumstances or obstacles that could challenge their success. For example, the recognition that songs sung by the children were not in a comfortable vocal range for the seniors required them to adjust and sing it down an octave or in a lower, unrelated key. This tendency to compensate is a testament to the personality of the individual. The findings then may suggest that the benefits to the singing program in an intergenerational format might outweigh the negative ramifications to their physical condition and fear of social rejection.

In summary, the data from the findings can be categorized into both positive benefits and challenges experienced by the seniors and revealed the aging adults' perspectives of intergenerational singing programs as either "opportunities for" or "difficulties because" in relation to their involvement and engagement in singing activities. These challenges in particular are interesting for researchers because they are the issues that could potentially interfere with the seniors functioning as musickers and engagers. However, one cannot assume that because older adults may be exhibiting physical signs of apathy, that they are not in fact feeling deeply and are uninvolved in the learning process. Even physically locating oneself on the periphery does not necessarily indicate disengagement or disaffection and certainly does not imply that learning is not taking place [19], [20]. Nor does it mean that the benefits noted by others are not also being experienced by the seemingly uninterested participants. The concept of fear was a recurring theme, as program leaders witnessed residents sitting on the periphery or peeking around the corner, reluctant to engage in musical collaboration. Extraneous factors, unknown to researchers, can prove difficult when assessing whether participants are demonstrating engagement or reluctance. As such, varying levels of engagement within certain circumstances have been proposed in the diagram below to account for this differentiation (Figure 1).

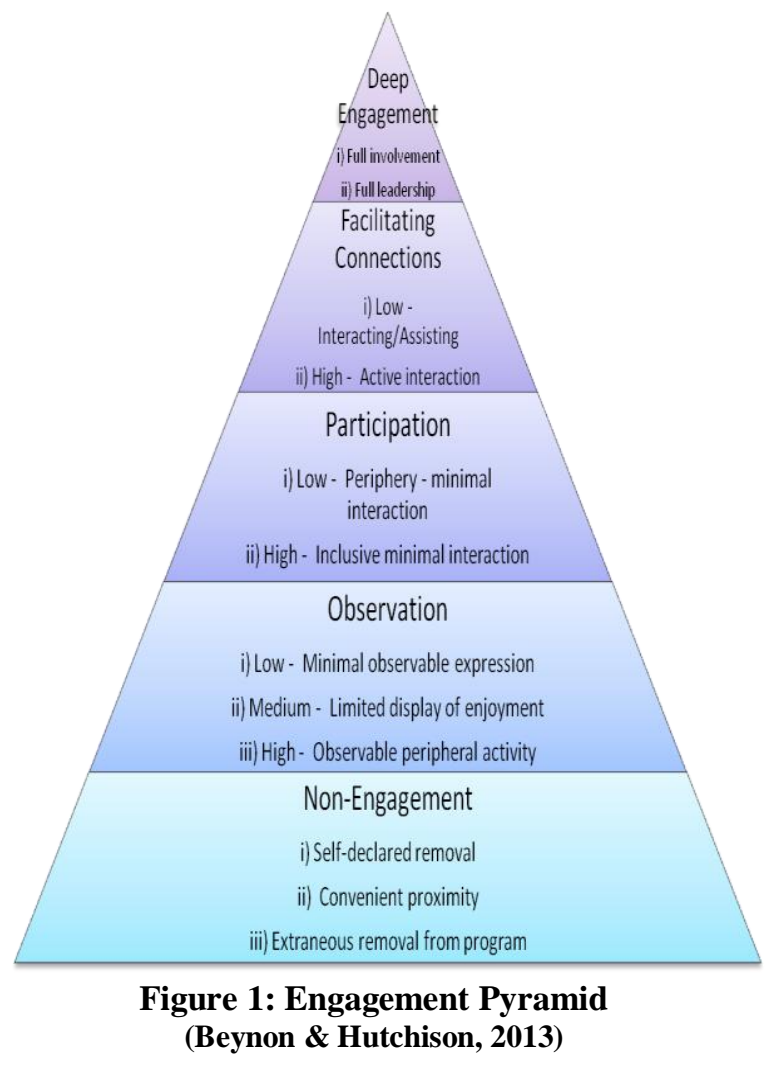

The headings, as shown in this pyramid structure, account for varying degrees of engagement, and are proportional to both the observed participation and attendance at sessions in which participation ranged from opting out; to observing from sidelines; to participating from the side; to the 20 who sang and interacted enthusiastically with the children. There is no doubt that it is both a challenge and a goal for leaders to facilitate and structure an inclusive IG model whereby all participants are deeply engaged; however, it would be inaccurate to assume that observers from the side are not engaged. Similarly to Small's affordances of musicking occurring in 
multifarious forms, we posit that this notion extends to musical engagement in the intergenerational singing program also.

\section{Conclusion}

Although this paper has focused on the limitations identified by the elderly participants, the sentiments expressed by the residents, school personnel, residence administration, and the genuine enthusiasm of the students during the program and through the interviews indicated that the positive outcomes of intergenerational fellowship outweighed the concerns raised. Indeed the IG singing helped some to overcome these limitations and great regret was expressed when the program ended. For researchers interested in the attitudes and perceptions of seniors participating in a shared singing experience, significant findings were revealed through observation and interview opportunities. While peripheral participation may be more desirable than core immersion for most residents, the positive outcomes of social co-operation are apparent for those who had the confidence - and in some cases, courage - to participate. Some residents joined the program solely for the opportunity to engage with children; others viewed it as an opportunity for social companionship with others; others endeavoured to learn from the students; some chose to inspire the younger generation; a few elected to educate the children; and others desired to inspire them. Many residents aimed to nurture and guide the children through the various activities and virtually all seniors allowed themselves to reminisce about songs from their past. Many seniors viewed the role of singing as a means to facilitate the building of relationships between themselves and the students. While the connections formed were definitely a reward, revelations of both senior and student behaviour and attitudes with respect to musicking surfaced as a result of this study. Apprehension was a common concern that manifested itself in different forms whether it was the fear of what was expected from the seniors in the sessions, the anxiety about whistling when one couldn't whistle, the concern of sitting in the wrong place and disturbing an existing seating arrangement - the concept of being anxious appears to be more likely a lack of confidence. The implications for further research into the connection of apprehension and confidence are needed to provide enlightenment about senior participation, involvement, behaviour and engagement in both musicking and social situations. Most notably, concern of judgment, perceived inadequacies of the residents' skill level and vocal physiological barriers, in addition to changing social roles can often manifest itself in behavioural tendencies during social situations. While the field of music education is only beginning to explore the outcomes of singing in an intergenerational context, the knowledge gained from this research initiative aims to assist community music educators who seek to provide opportunities which connect generations and support well-being through the medium of singing.

\section{References}

[1] C.A. Beynon, R. Heydon, S.A. O'Neill, Z. Zhang, and W. Crocker, "Straining to hear the singing: Toward an understanding of successful intergenerational singing curriculum", Journal of Intergenerational Relationships, Routledge, 2013, pp. 176-189.

[2] C. Small, "Musicking - The means of performing and listening", Music Education Research, Routledge, 1999, pp. 9-21.

[3] J. Russell, M. Ainley, and E. Frydenberg, "Student motivation and engagement", Department of Education and Training, Canberra, 2005.

[4] J. Reeve, H. Jang, D. Carrell, S. Jeon, and J. Barch, "Enhancing students' engagement by increasing teachers' autonomy support", Motivation and Emotion, Springer, 2004, pp. 147-169.

[5] B. Friedman, "The integration of pro-active aging education into existing educational curricula", Journal of Gerontological Social Work, Routledge, 1997, pp. 103110 .

[6] Harste, J. C., V.A. Woodward, and C.L. Burke, Language stories and literacy lessons, Heinemann, Portsmouth, 1984.

[7] R. Sataloff, D.C. Rosen, M. Hawkshaw, and J.R. Spiegel, "The three ages of voice: The aging adult voice", Journal of Voice, The Voice Foundation, 1997, pp. 156160.

[8] A.J. Caruso, P.B. Mueller, and B.B. Shadden, "Effects of aging on speech and voice", Physical \& Occupational Therapy in Geriatrics, Informa Plc., 1995, pp. 63-79.

[9] R. Sataloff, "On the voice: Vocal aging and its medical implications", Choral Journal, American Choral Directors Association, 2000, pp. 57-63.

[10] S.E. Linville, "The aging voice", ASHA Leader, American Speech-Language-Hearing Association, 2004, pp. 12-21.

[11] Meredith, V., Sing better as you age: A comprehensive guide for adult choral musicians, Santa Barbara Music Publishing, Inc., California, 2007.

[12] D.C. Freed, "Working with aging singers", The American Organist, American Guild of Organists, 2008, pp. 76-77.

[13] K. Brunssen, "The evolving voice: Profound at every age", Choral Journal, American Choral Directors Association, 2010, pp. 45-51. 
[14] Linville, S.E., Vocal aging, Singular, San Diego, 2001.

[15] K. DeJardin, "With voices joined: Working with aging voices", Pastoral Music, National Association of Pastoral Musicians, 2010, pp. 28-30.

[16] Novak, M., Issues in aging, Pearson Education, Inc., Boston, 2006.

[17] S. Rayapati, "Teaching reaches out: Class voice and the aging singer", Journal of Singing, National Association of Teachers of Singing, 2008, pp. 543-550.

[18] Rowe, J.W., and R.L. Kahn, Successful aging, Pantheon Books, New York, 1998.

[19] Green, L., How popular musicians learn: A way ahead for music education, Ashgate Press, Aldershot, 2001.

[20] Green, L., Music, informal learning and the school: A new classroom pedagogy, Ashgate Press, Aldershot, 2008. 